
\title{
$\begin{array}{ll}\text { Research Square } & \begin{array}{l}\text { Preprints are preliminary reports that have not undergone peer review. } \\ \text { They should not be considered conclusive, used to inform clinical practice, } \\ \text { or referenced by the media as validated information. }\end{array}\end{array}$
}

\section{Vaginal progesterone supplementation in the management of preterm labor: A randomized controlled trial}

\section{Ratanawadee Sirisangwon}

Placental Related Diseases Research Unit, Department of Obstetrics and Gynecology, Faculty of Medicine,

Vorapong Phupong ( $\square$ vorapong.p@chula.ac.th )

Chulalongkorn University https://orcid.org/0000-0003-0151-9595

\section{Research}

Keywords: preterm labor, micronized progesterone, vagina, latency period, supplementation

Posted Date: February 19th, 2020

DOI: https://doi.org/10.21203/rs.2.23972/v1

License: (c) (i) This work is licensed under a Creative Commons Attribution 4.0 International License.

Read Full License

Version of Record: A version of this preprint was published at Maternal and Child Health Journal on April 26th, 2021. See the published version at https://doi.org/10.1007/s10995-021-03153-z. 


\section{Abstract}

\section{Background}

Preterm labor is a common obstetric complication and can lead to preterm delivery. Preterm birth or preterm delivery is the leading cause of neonatal morbidity and mortality, especially when preterm birth occurs at a gestational age less than 34 weeks. The primary objective in this study was to evaluate the effects of vaginal progesterone supplementation for the prolongation of the latency period in preterm labor. The secondary objectives were to evaluate gestational age at delivery, rates of preterm birth less than 34 and 37 weeks, obstetric outcomes, maternal compliance with medication use, and side effects.

\section{Methods}

A randomized controlled trial was performed. Ninety women with preterm labor occurring at 24 to 34 weeks were either randomized to a vaginal progesterone group (44 women) receiving tocolytic and antenatal corticosteroids treatment combined with vaginal micronized progesterone (400 mg everyday) or to the no-progesterone group (46 women) receiving tocolytic and antenatal corticosteroids treatment only.

\section{Results}

Latency periods were more prolonged in the vaginal progesterone group than in the no-progesterone group ( $32.8 \pm 18.7$ vs. $25.8 \pm 22.7$ days, $p=0.045$ ). Gestational age at delivery in the vaginal progesterone group was also higher than in the no-progesterone group $(36.5 \pm 2.9$ vs. $34.9 \pm 3.7$ weeks, $p$ $=0.022)$. There were significant reduction rates of preterm birth less than 34 weeks $(13.6 \%$ vs. $39.1 \%, p=$ $0.012)$, low birth weight $(29.5 \%$ vs. $50 \%, p=0.048)$, neonatal respiratory distress syndrome $(13.6 \%$ vs. $37 \%, p=0.021)$, and neonatal intensive care unit admission ( $6.8 \%$ vs. $28.3 \%, p=0.017)$.

\section{Conclusion}

Combined treatment with vaginal progesterone $400 \mathrm{mg}$ could prolong the latency period in preterm labor when compared with no progesterone. Further, this approach could decrease the rates of preterm birth less than 34 weeks, low birth weight, and neonatal respiratory distress syndrome.

\section{Background}

Preterm birth is one of the more common obstetric complications. The rate of preterm birth ranges from $5 \%$ to $18 \%$ [1]. Preterm birth is diagnosed when delivery occurs between 20 to $36^{+6}$ weeks of pregnancy [2]. It causes neonatal mortality and is the most common reason for antenatal hospitalization, especially when preterm birth occurs at a gestational age (GA) less than 34 weeks. Preterm birth causes neonatal prematurity-related morbidities and neonatal death [2]. Preterm labor is diagnosed as spontaneous labor occurring at GAs less than 37 weeks, and which generally leads to preterm birth. Thus, the proper management of preterm labor can decrease cases of preterm birth. Proper treatment during preterm labor 
includes tocolytic drug and antenatal corticosteroids. A tocolytic drug is a short-term medication used in preterm labor for two days. The two-day time provided allows for efforts to improve fetal lung maturity to be enacted by corticosteroid administration $[3,4]$.

Progesterone is a hormone with a proven ability to maintain uterine quiescence [5]. It is useful for allowing a pregnancy to reach its physiologic term. At sufficient levels in the myometrium, progesterone blocks the oxytocin effect of prostaglandin $\mathrm{F} 2 \mathrm{a}$ and a-adrenergic stimulation and therefore increases the a-adrenergic tocolytic response. Natural progesterone is free of any disturbing teratogenic, metabolic, or hemodynamic effects [6, 7].

In 2012, the American College of Obstetricians and Gynecologists recommended using prophylactic vaginal progesterone in women with a short cervical length for the prevention of preterm birth [8]. Various forms of progesterone such as 17 a-hydroxyprogesterone caproate intramuscular injection, vaginal progesterone gel, and vaginal progesterone tablet were investigated to prevent preterm delivery in women with a singleton gestation and a prior spontaneous preterm singleton birth [8]. Recently, a meta-analysis of individual patient data demonstrated that vaginal progesterone decreases the risk of preterm birth in singleton gestations with a short cervix without deleterious effects on childhood neurodevelopment [9]. However, there have been no recommendations for using maintenance progesterone after preterm labor management for the prevention of preterm birth. Randomized clinical studies evaluating the use of vaginal progesterone for the maintenance of tocolysis after an episode of threatened preterm labor and preterm labor have produced conflicting data. Some research found that vaginal progesterone maintenance therapy after successful parenteral tocolysis did not significantly reduce the rate of preterm birth [5, 10-12]. Some studies found a significantly longer latency period $[5,10]$, while one study did not find a longer latency period [12]. Due to these conflicting results, this study sought to assess the effects of vaginal progesterone supplementation for the prolongation of the latency period in preterm labor. The secondary objectives were to assess GA at delivery, rates of preterm delivery less than 34 and 37 weeks, obstetric outcomes, maternal compliance with medication use, and side effects.

\section{Methods}

This randomized controlled study was performed at King Chulalongkorn Memorial Hospital, Department of Obstetrics and Gynecology, Faculty of Medicine, Chulalongkorn University, Bangkok, Thailand, between June 2017 and July 2018. This study was approved by the Institute Research Ethics Committee and was registered at ClinicalTrials.gov (Clinical trials registration no. NCT03202836; registered on June 29, 2017). All participants gave written informed consent. The methods were performed in accordance with approved standard guidelines adhering to the Declaration of Helsinki.

Singleton pregnant women aged 18 to 45 years who presented to the labor room with preterm labor with intact membranes at 24 to 34 weeks of pregnancy were invited to participate. Preterm labor was diagnosed as having a regular uterine contraction combined with changes in cervical dilatation or effacement [2]. Exclusion criteria included pregnant women with contraindications to tocolytic drugs, 
maternal or fetal conditions that required immediate delivery, cervical dilatation of $5 \mathrm{~cm}$ or more, "incompatibility with-life" fetal anomalies, fetal death, and allergy to progesterone.

Eligible women were enrolled after the study was approved. Pelvic examination was performed to assess cervical dilatation and effacement. A tocometer was used to measure uterine contractions. Cervical effacement, dilatation, and uterine contraction data were obtained. Baseline ultrasonography was performed to confirm GA and to obtain the estimated fetal weight. All participants received oral nifedipine, oral indomethacin, or intravenous terbutaline for 48 hours of tocolytic and received a total of four doses of dexamethasone ( $6 \mathrm{mg}$ intramuscularly every 12 hours). The dosage of nifedipine first involved loading 10-mg doses every 30 minutes for two doses, which then continued with 10 to $20 \mathrm{mg}$ every six hours. The dosage of indomethacin was started a loading 50-mg dose of indomethacin and then continued with 25 to $50 \mathrm{mg}$ every six hours. The dosage of terbutaline was 5 to $10 \mathrm{mg} / \mathrm{min}$ administered intravenously.

Prior to the study, the co-investigator generated the allocation sequence. This co-investigator had no contact with participants. The opaque envelopes which contained a code for the vaginal progesterone group or no-progesterone group were sequenced in numerical order to ensure randomization. Participants were randomized into two groups: a vaginal progesterone group or no-progesterone group. A block-of-four technique by random-number table was used for randomization. Nurses at the labor room enrolled, selected a sequentially numbered opaque envelope when a study woman met the inclusion criteria, and allocated women to their respective groups.

In addition, other opaque envelopes containing 28 or 14 capsules of micronized progesterone were labeled. These opaque envelopes were used in only the vaginal progesterone group. Drugs were prepared by a pharmacist who was not involved in the study at a point prior to the study. Fourteen-capsule and 28capsule opaque envelopes were used for women with one-week and two-week follow-up periods, respectively. Micronized progesterone (Utrogestan ${ }^{\circledR} 200$ mg/capsule; Besins Healthcare, Bangkok, Thailand) was assigned to the vaginal progesterone group, while the no-progesterone group did not receive this medication. Drug use was initiated at the beginning of treatment with tocolysis. The drug dosage was two capsules applied to the vagina daily. Treatment was continued until $36^{+6}$ weeks or until delivery. Women were admitted until uterine contractions stopped. The follow-up protocol from a previous study was used $[3,4]$. Women recorded their uterine contractions and were followed-up with two-week and one-week intervals until delivery. If the GA was less than 36 weeks, women were followed-up with a two-week interval. If the $\mathrm{GA} \geq 36$ weeks, women were followed-up with a one-week interval until delivery. Women in the vaginal progesterone group had to return their opaque envelopes to review their compliance at each follow-up time and at delivery. Good compliance meant that the women used all prescribed study medications.

The primary outcome was to evaluate the latency period (the time from the onset of preterm labor until birth). The secondary outcomes were to evaluate GA at delivery, rates of preterm delivery less than 34 weeks and 37 weeks, obstetric outcomes, maternal compliance with medication use, and side effects. 
The sample size was calculated from the latency period from a previous study ${ }^{[10]}$. The means \pm standard deviations of the latency period were $32.1 \pm 17.8$ days and $21.2 \pm 16.3$ days in the vaginal progesterone group and control group, respectively. At least 39 participants in each group were needed to detect a statistical difference $(\beta=0.2, a=0.05)$. To allow for a loss to follow-up rate of $15 \%$, a total of 90 participants were needed in the study.

\section{Statistical analysis}

Statistical analysis was performed by SPSS version 22 (IBM Corp., Armonk, NY, USA). An independent ttest and analysis of covariance were used for comparing continuous data. The chi-squared test and Fisher exact test were used for comparing categorical data. The Mann-Whitney $U$ test was used for comparing nonparametric data. A p value less than 0.05 was deemed statistically significant. An intentto-treat (ITT) analysis was used for analysis purposes in this trial.

\section{Results}

Ninety women were enrolled into this study. All participants were randomly allocated to the two groups, with 44 receiving vaginal progesterone and 46 receiving no progesterone (Figure 1). One woman in the no-progesterone group was lost to follow-up. However, 90 women were included in the ITT analysis. Regarding demographic characteristics (i.e., age, gravidity, parity, GA, history of preterm birth, body mass index, cervical dilatation, blood pressure, type of tocolysis, and dexamethasone administration), there were no significant differences between the groups (Table 1).

Latency periods were prolonged in the vaginal progesterone group more so than in the no-progesterone group (32.8 \pm 18.7 days vs. $25.8 \pm 22.7$ days, $p=0.045$ ) (Table 2 ). Further, GA at delivery in the vaginal progesterone group was higher than no-progesterone group ( $36.5 \pm 2.9$ weeks vs. $34.9 \pm 3.7$ weeks, $p=$ 0.022). There was also a significant reduction rate in preterm delivery occurring less than 34 weeks $(13.6 \%$ vs. $39.1 \%, p=0.012)$. Conversely, there were no differences in rate of preterm delivery less than 37 weeks, mode of delivery, pregnancy complications, re-admission rate, and length of hospital stay (Table 2).

Compliance in the vaginal progesterone group was good [37/44 (84\%)]. Side effects occurred in 14 cases (31.8\%), including six cases of vaginal discharge (13.6\%), four cases of vaginal itching $(9.1 \%)$, three cases of dizziness $(6.8 \%)$ and one case of nausea/vomiting (2.3\%).

Table 3 shows neonatal outcomes. Birth weight was significantly higher in the vaginal progesterone group than in the no-progesterone group. Low birth weight (LBW), respiratory distress syndrome (RDS), and admission to the neonatal intensive care unit (NICU) were significantly less prominent in the vaginal progesterone group than in the no-progesterone group. There were no differences between the groups regarding Apgar scores of less than 7 at one and five minutes, bronchopulmonary dysplasia (BPD), intraventricular hemorrhage (IVH), necrotizing enterocolitis (NEC), sepsis, jaundice due to prematurity, days of neonatal hospitalization, and neonatal mortality. 


\section{Discussion}

This randomized controlled study evaluated the efficacy of vaginal progesterone in preterm labor treated with tocolysis and corticosteroids. This study showed that the latency period was prolonged in the vaginal progesterone group more so than in the no-progesterone group. GA at delivery in the vaginal progesterone group was also more than in the no-progesterone group. Further, there were significant reduction rates in preterm delivery less than 34 weeks, LBW, and rate of neonatal respiratory distress syndrome. Similar results between groups were found in terms of the rate of preterm delivery less than 37 weeks, obstetric outcomes, other neonatal outcomes, maternal compliance with medication use, and side effects.

In this study, the latency period was prolonged more so in the vaginal progesterone group than in the noprogesterone group (32.8 days vs. 25.8 days, $p=0.045$ ). This finding was consistent with those of prior studies that assessed vaginal micronized progestogen in women with threatened preterm labor $[5,10,13$, 14]. In their treatment efforts, one study used $400 \mathrm{mg}$ of vaginal progesterone [5] while some studies employed $200 \mathrm{mg}$ of vaginal progesterone [13]. This present finding was in contrast with Noblot et al' study (1991)[15]. These authors assessed the maintenance of tocolysis with oral micronized progesterone $400 \mathrm{mg}$ in cases of preterm labor and found no difference in the latency period [15]. Of note, differences between this prior research and our study may be from the different route of medication used.

The results of this study were also different from those of our previous study that assessed oral dydrogesterone $20 \mathrm{mg}$ in the adjunctive management of preterm labor. There, latency periods were not different between the groups [4]. The difference between the studies may be due to the difference in type of progesterone and the route of drug administration used.

Vaginal micronized progesterone was chosen for use in the present study because the vaginal route enhanced the bioavailability and the absence of undesirable side-effects such as sleepiness, fatigue, or headache $[5,16]$. Micronized progesterone $400 \mathrm{mg}$ was used in this study, similar to in a previous study [5].

In the present study, the rate of preterm delivery less than 34 weeks was significantly reduced in the vaginal progesterone group. This finding was consistent with that in a previous study [17], where the authors reviewed the use of vaginal progesterone $200 \mathrm{mg}$ in threatened preterm labor after tocolysis. They found that vaginal progesterone reduced preterm delivery before 34 weeks when compared with no medication [17]. However, this finding was in contrast with other results in previous studies [11-13], where the authors found that the rates of preterm delivery less than 34 and 37 weeks were not significantly reduced when compared with placebo [11]. The difference in results between these studies could be attributed to the variations in the study population, dose of vaginal progesterone, and time of starting progesterone.

A recent systemic review and meta-analysis compared vaginal progesterone, oral progesterone, $17 \mathrm{a}$ hydroxyprogesterone caproate, cerclage, and pessary for preventing preterm birth in at-risk singleton 
pregnancies. The study notably found that vaginal progesterone was the only intervention with a consistent level of effectiveness for preventing preterm birth in singleton at-risk pregnancies overall and in those with a previous preterm birth [18].

Neonatal outcomes including birth weight were higher, and LBW, RDS, and NICU admission were reduced in the vaginal progesterone group than in the no-progesterone group. This may be explained by the higher GA at delivery and the reduced rate of preterm delivery less than 34 weeks in the vaginal progesterone group.

The mechanisms of progesterone for prolonging pregnancy are not clearly understood, but progesterone inhibits myometrial activity by way of several mechanisms. Specifically, progesterone suppresses genes that regulate uterine contractions (i.e., genes for calcium channels, oxytocin receptors, and the gap junction protein connexin), upregulates relaxation mechanisms (i.e., the generation and action of cyclic adenosine monophosphate, and cyclic guanosine monophosphate), and acts by opposing estrogen, which increases myometrial contractility [19]. In a human study from Lucovnik et al, it was found that maintenance tocolysis with $400 \mathrm{mg}$ of vaginal micronized progesterone reduced the propagation velocity of electrical signals within the myometrium [20].

A strength of this study was that it was a randomized controlled study conducted to assess the efficacy of vaginal micronized progesterone for both tocolytic and the maintenance treatment of preterm labor. Vaginal micronized progesterone was chosen in the present study because the vaginal route enhances bioavailability and had no undesirable known side-effects such as sleepiness, fatigue, and headache [5, 16]. Micronized progesterone $400 \mathrm{mg}$ was used in this study like in a previous study [5]. A limitation of this study was that it was not a placebo-controlled trial and a limitation of sample size in the vaginal progesterone group. Future randomized, placebo-controlled studies with larger sample sizes should be performed to evaluate the value of vaginal micronized progesterone as a secondary prevention method in preterm labor.

\section{Conclusions}

Combined treatment with vaginal progesterone $400 \mathrm{mg}$ in preterm labor could prolong the latency period as compared with no progesterone. It also decreased the rate of preterm delivery less than 34 weeks, LBW and RDS.

\section{Abbreviations}

RDS: respiratory distress syndrome; IVH: intraventricular hemorrhage; NEC: necrotizing enterocolitis; ACOG: American College of Obstetricians and Gynecologists; ITT: intent-to-treat; BMI: body mass index; NICU: neonatal intensive care unit; BPD: bronchopulmonary dysplasia

\section{Declarations}




\section{Ethics approval and consent to participate}

The study protocol was approved by the Research Ethics Committee of the Faculty of Medicine, Chulalongkorn University. IRB no. 034/60

\section{Consent for publication}

Not applicable for this study.

\section{Availability of data and materials}

The ethical approval did not include permission to disclose the data publicly. It can be made available by the authors upon reasonable request.

\section{Competing interests}

The authors declare that they have no competing interests.

\section{Funding}

The work was funding by Internal research grant: Ratchadapiseksompotch Fund, Faculty of Medicine, Chulalongkorn University, study grant number RA60/092.

The funding body did not involve in the design of the study; collection, analysis, and interpretation of data; and in writing the manuscript.

\section{Authors' contributions}

RS and VP concepted the study design and participated in the collection of data. VP analyzed data. RS and VP wrote, edited and reviewed the manuscript, and approved the final version for publication.

\section{Acknowledgments}

The authors thank the doctors and nurses of the antenatal care unit and labor room, Department of OB\&GYN, Faculty of Medicine, King Chulalongkorn Memorial Hospital and Chulalongkorn University for their help.

\section{References}

1. Blencowe H, Cousens S, Oestergaard MZ, Chou D, Moller AB, Narwal R, Adler A, Vera Garcia C, Rohde S, Say L, et al. National, regional, and worldwide estimates of preterm birth rates in the year 2010 with time trends since 1990 for selected countries: a systematic analysis and implications. Lancet 2012;379(9832):2162-72.

2. ACOG practice bulletin no. 171. Management of preterm labor. Obstet Gynecol 2016; 128(4):e155e164. 
3. Theplib A, Phupong V. Success rate of terbutaline in inhibiting preterm labor for $48 \mathrm{~h}$. J Matern Fetal Neonatal Med 2016; 29(5):841-4.

4. Areeruk W, Phupong V. A randomized, double blinded, placebo controlled trial of oral dydrogesterone supplementation in the management of preterm labor. Sci Rep 2016; 6:20638.

5. Borna S, Sahabi N. Progesterone for maintenance tocolytic therapy after threatened preterm labour: A randomised controlled trial. Aust NZ J Obstet Gynaecol 2008; 48(1):58-63.

6. da Fonseca EB, Bittar RE, Carvalho MHB, Zugaib M. Prophylactic administration of progesterone by vaginal suppository to reduce the incidence of spontaneous preterm birth in women at increased risk: A randomized placebo-controlled double-blind study. Am J Obstet Gynecol 2003; 188(2):419-24.

7. Fuchs AR, Fuchs F. Endocrinology of human parturition: a review. Br J Obstet Gynaecol 1984; 91(10):948-67.

8. Practice bulletin no. 130. prediction and prevention of preterm birth. Obstet Gynecol 2012; 120(4):964-73.

9. Romero R, Conde-Agudelo A, Da Fonseca E, O'Brien JM, Cetingoz E, Creasy GW, Hassan SS, Nicolaides $\mathrm{KH}$. Vaginal progesterone for preventing preterm birth and adverse perinatal outcomes in singleton gestations with a short cervix: a meta-analysis of individual patient data. Am J Obstet Gynecol 2018; 218(2):161-80.

10. Arikan I, Barut A, Harma M, Harma IM. Effect of Progesterone as a Tocolytic and in Maintenance Therapy during Preterm Labor. Gynecol Obstet Invest 2011; 72(4):269-73.

11. Palacio M, Cobo T, Antolin E, Ramirez M, Cabrera F, de Rosales FM, Bartha JL, Juan M, Marti A, Oros $D$, et al. Vaginal progesterone as maintenance treatment after an episode of preterm labour (PROMISE) study: a multicentre, double-blind, randomised, placebo-controlled trial. BJOG 2016; 123(12):1990-9.

12. de Tejada BM, Karolinski A, Ocampo MC, Laterra C, Hosli I, Fernandez D, Surbek D, Huespe M, Drack $G$, Bunader $A$, et al. Prevention of preterm delivery with vaginal progesterone in women with preterm labour (4P): randomised double-blind placebo-controlled trial. BJOG 2015; 122(1):80-91.

13. Sharami SH, Zahiri Z, Shakiba M, Milani F. Maintenance therapy by vaginal progesterone after threatened idiopathic preterm labor: A randomized placebo-controlled double-blind trial. Int J Fertil Steril 2010; 4(2):45-50.

14. Areia A, Fonseca E, Moura P. Progesterone use after successful treatment of threatened pre-term delivery. J Obstet Gynaecol 2013; 33(7):678-681.

15. Noblot G, Audra P, Dargent D, Faguer B, Mellier G: The use of micronized progesterone in the treatment of menace of preterm delivery. Eur J Obstet Gynecol Reprod Biol 1991; 40(3):203-9.

16. Friedler S, Raziel A, Schachter M, Strassburger D, Bukovsky I, Ron-El R. Luteal support with micronized progesterone following in-vitro fertilization using a down-regulation protocol with gonadotrophin-releasing hormone agonist: a comparative study between vaginal and oral administration. Hum Reprod 1999; 14(8):1944-8. 
17. Bomba-Opon DA, Kosinska-Kaczynska K, Kosinski P, Wegrzyn P, Kaczynski B, Wielgos M. Vaginal progesterone after tocolytic therapy in threatened preterm labor. J Matern Fetal Neonat Med 2012; 25(7):1156-9.

18. Jarde A, Lutsiv O, Beyene J, McDonald SD. Vaginal progesterone, oral progesterone, 17-OHPC, cerclage, and pessary for preventing preterm birth in at-risk singleton pregnancies: an updated systematic review and network meta-analysis. BJOG 2019; 126(5):556-67.

19. Garfield RE, Saade G, Buhimschi C, Buhimschi I, Shi L, Shi SQ, Chwalisz K. Control and assessment of the uterus and cervix during pregnancy and labour. Hum Reprod Update 1998; 4(5):673-95.

20. Lucovnik M, Bregar AT, Bombac L, Gersak K, Garfield RE. Effects of vaginal progesterone for maintenance tocolysis on uterine electrical activity. J Obstet Gynaecol Res 2018; 44(3):408-16.

\section{Tables}

Table 1. Demographic characteristics between groups. 


\begin{tabular}{|c|c|c|c|}
\hline Characteristics & $\begin{array}{l}\text { Vaginal progesterone } \\
\text { group }(\mathrm{n}=44)\end{array}$ & $\begin{array}{l}\text { No vaginal progesterone } \\
\text { group }(\mathrm{n}=46)\end{array}$ & $\begin{array}{l}\mathrm{p} \\
\text { value }\end{array}$ \\
\hline Age & $29.5 \pm 6.9$ & $30.0 \pm 5.9$ & 0.712 \\
\hline Gravidity & & & 0.398 \\
\hline - Primigravida & $20(45.5 \%)$ & $25(54.3 \%)$ & \\
\hline - Multigravida & $24(54.5 \%)$ & $21(45.7 \%)$ & \\
\hline Parity & & & 0.143 \\
\hline - Nulliparous & $22(50 \%)$ & $30(65.2 \%)$ & \\
\hline - $\quad$ Multiparous & $22(50 \%)$ & $16(34.8 \%)$ & \\
\hline History of preterm birth & $5(11.4 \%)$ & $3(6.5 \%)$ & 0.48 \\
\hline BMI $\left(\mathrm{kg} / \mathrm{m}^{2}\right)$ & $21.7 \pm 4.2$ & $21.5 \pm 4.1$ & 0.77 \\
\hline GA at admission (days) & $31.9 \pm 2.0$ & $30.9 \pm 2.5$ & 0.05 \\
\hline $\begin{array}{l}\text { Median of cervical } \\
\text { dilatation }(\mathrm{cm})\end{array}$ & 1 & 1 & 0.858 \\
\hline $\begin{array}{l}\text { Systolic blood pressure } \\
(\mathrm{mmHg})\end{array}$ & $111.6 \pm 11.9$ & $114.2 \pm 11.3$ & 0.274 \\
\hline $\begin{array}{l}\text { Diastolic blood pressure } \\
(\mathrm{mmHg})\end{array}$ & $68.6 \pm 8.4$ & $70.1 \pm 8.5$ & 0.418 \\
\hline Type of tocolysis & & & 0.13 \\
\hline - Nifedipine & $40(90.9 \%)$ & $37(80.4 \%)$ & \\
\hline - Terbutaline & $3(6.8 \%)$ & $9(19.6 \%)$ & \\
\hline - Indomethacin & $1(2.3 \%)$ & 0 & \\
\hline $\begin{array}{l}\text { Dexamethasone } \\
\text { administration }\end{array}$ & $44(100 \%)$ & $46(100 \%)$ & 1.000 \\
\hline
\end{tabular}

Data presented as mean \pm SD or $n(\%)$. BMI: body mass index, GA: gestational age.

Table 2. Latency periods, gestational age at delivery, percentage of birth $<34$ and $<37$ weeks, and obstetric outcomes between groups. 


\begin{tabular}{llll}
\hline & $\begin{array}{l}\text { Vaginal progesterone } \\
\text { group }(\mathrm{n}=44)\end{array}$ & $\begin{array}{l}\text { No vaginal progesterone } \\
\text { group (n=46) }\end{array}$ & $\begin{array}{l}\mathrm{p} \\
\text { value }\end{array}$ \\
\hline $\begin{array}{l}\text { latency periods (days) } \\
\text { GA at delivery (days) }\end{array}$ & $32.8 \pm 18.7$ & $25.8 \pm 22.7$ & 0.045 \\
Delivery & $34.9 \pm 3.7$ & 0.022 \\
$<34$ weeks & $6(13.6 \%)$ & $18(39.1 \%)$ & 0.012 \\
$<37$ weeks & $19(43.2 \%)$ & $28(60.9 \%)$ & 0.093 \\
Mode of delivery & & $24(52.2 \%)$ & 0.509 \\
-Vaginal delivery & $26(59.1 \%)$ & $22(47.8 \%)$ & 0.531 \\
-Cesarean section & $18(40.9 \%)$ & $8(17.4 \%)$ & \\
Re-admission (due to & $11(25 \%)$ & & 0.227 \\
preterm labor) & & $5(4,10)$ & \\
Median of LOS & $4(3,6.7)$ & & \\
(Maternal) & & & \\
\hline
\end{tabular}

Data presented as mean $\pm \mathrm{SD}, \mathrm{n}(\%)$, and median (interquartile range). GA: gestational age, LOS: Length of hospital stay.

Table 3. Neonatal outcomes between groups. 


\begin{tabular}{|c|c|c|c|}
\hline Character & $\begin{array}{l}\text { Vaginal progesterone } \\
\text { group }(\mathrm{n}=44)\end{array}$ & $\begin{array}{l}\text { No vaginal progesterone } \\
\text { group }(n=46)\end{array}$ & $\begin{array}{l}\mathrm{p} \\
\text { value }\end{array}$ \\
\hline Birth weight (grams) & $2,699.4 \pm 697.2$ & $2,382.3 \pm 772.5$ & 0.044 \\
\hline Low birth weight & $13(29.5 \%)$ & $23(50 \%)$ & 0.048 \\
\hline \multicolumn{4}{|l|}{ Apgar scores } \\
\hline At $1 \min <7$ & $4(9.1 \%)$ & $7(15.2 \%)$ & 0.571 \\
\hline At $5 \min <7$ & $1(2.3 \%)$ & $1(2.2 \%)$ & 1.000 \\
\hline \multicolumn{4}{|l|}{ Neonatal complications } \\
\hline$-\mathrm{RDS}$ & $6(13.6 \%)$ & 17 (37\%) & 0.021 \\
\hline$-\mathrm{BPD}$ & 0 & $1(2.2 \%)$ & 1.000 \\
\hline$-\mathrm{IVH}$ & 0 & $1(2.2 \%)$ & 1.000 \\
\hline$-\mathrm{NEC}$ & 0 & 0 & 1.000 \\
\hline -Sepsis & $4(9.1 \%)$ & $10(21.7 \%)$ & 0.172 \\
\hline $\begin{array}{l}\text {-Neonatal jaundice due to } \\
\text { prematurity }\end{array}$ & $10(22.7 \%)$ & $18(39.1 \%)$ & 0.146 \\
\hline $\begin{array}{l}\text {-NICU } \\
\text { admission }\end{array}$ & $3(6.8 \%)$ & $13(28.3 \%)$ & 0.017 \\
\hline Mortality & $1(2.3 \%)$ & 0 & 0.488 \\
\hline $\begin{array}{l}\text { Median day of } \\
\text { hospitalization (days) }\end{array}$ & $4(3,7)$ & $6.5(4,20.3)$ & 0.053 \\
\hline
\end{tabular}

Data presented as mean \pm SD, $\mathrm{n}(\%)$, and median (interquartile range). RDS: respiratory distress syndrome, BPD: Bronchopulmonary dysplasia, IVH: intraventricular hemorrhage, NEC: necrotizing enterocolitis, NICU: neonatal intensive care unit.

\section{Figures}




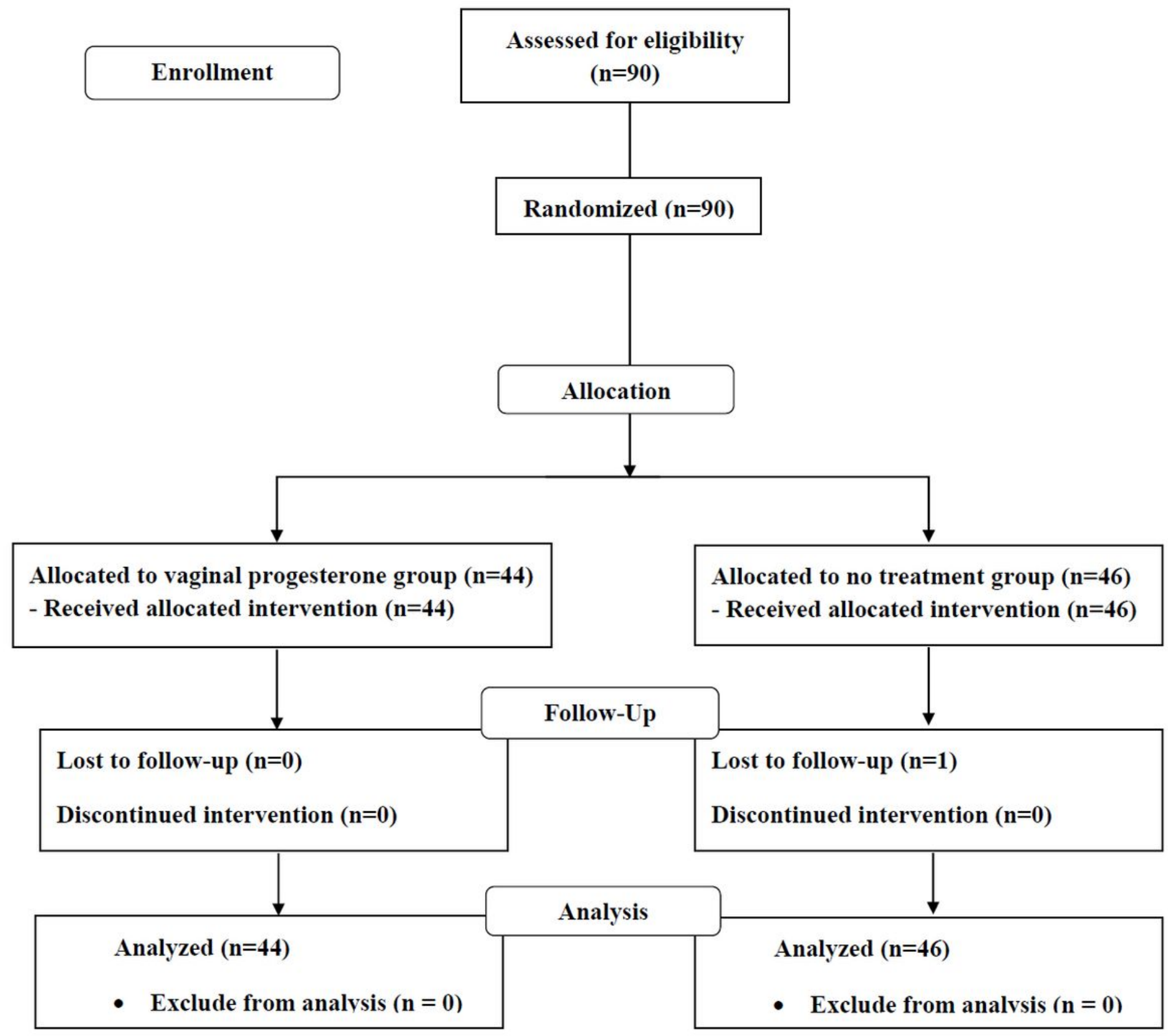

Figure 1

Profile of patient follow-up following randomization to either vaginal progesterone or no vaginal progesterone group. 